\title{
Routine intra-operative cholangiography for safe laparoscopic cholecystectomy and single stage laparoscopic choledocholithotomy
}

\author{
Ayman Soliman, ${ }^{a} M D$; Werner Muller, ${ }^{b} M D$; Stefan Ebner, ${ }^{b} M D$; \\ G Scinicz, ${ }^{b} M D$
}

a) Depertment of General Surgery, Ain Shams University Hospital - Cairo- Egypt

b) Depertment of General and Minimal Invasive Surgery - Landeskrankenhaus

Bregenz-Bregenz-Austria

(Presented in the congress of Egyptian Society of Laparoscopic Surgery, Cairo - Egypt; January 2007 \& accepted in 15th International congress of the European Association for Endoscopic Surgery (EAES), Athens - Greece; July 2007, also accepted at the Internet Journal of Surgery)

\begin{abstract}
Background: While laparoscopic cholecystectomy is widely accepted for therapy of cholecystolithiasis, controversy still exists concerning the routine use of intra-operative cholangiography $(I O C)$ during laparoscopic cholecystectomy $(L C)$ and its role in management of common bile duct stones at the same procedure whether it is discovered accidentally or expected as a single stage procedure if respective experience is available.

Methods: During laparoscopic cholecystectomy a cholangiography via the cystic duct is routinely performed. If bile duct stones are detected they are retrieved via the cystic duct or via incision of the common bile duct by insertion of a Fogarty catheter or Dormia basket. Exclusion criteria against simultaneous laparoscopic management include suspicious of malignancy, severe pancreatitis or cholangitis.

Results: From July 2005 to June 2007, 172 patients primarily underwent laparoscopic cholecystectomy at Landeskrankenhaus Bregenz (170 cases) \& at Ain Shams Specialized Hospital (2 cases), IOC was successful in 157 (91.2\%). Bile duct stones were found in 26 patients (15.1\%), dilated ducts without stones in 6 patients (3.4\%), and anatomic variations in 3 patients $(1.7 \%)$. Retrieval was performed via cystic duct and common bile duct in 15 and 11 cases respectively with complete removal. There were $2(1.1 \%)$ minor injuries of the bile duct, which were identified with IOC and repaired at the time of cholecystectomy without any consequences for the patients, while in 3 patients (1.7\%) Cholecystography was done for difficult identification of cystic duct and acute inflamed gall bladder.

Conclusion: Routine intra-operative cholangiography is feasible, provides valuable information about the anatomy of the biliary tract and might aid in the prevention of bile duct injuries, thereby improving the safety of laparoscopic cholecystectomy. Also, when correct indications and surgical expertise are available, simultaneous laparoscopic management of common bile duct stones represent a safe and minimally invasive alternative to a two stage procedure approach.
\end{abstract}

Key Words: Intra-operative cholangiography, common bile duct stones, laparoscopic cholecystectomy. 


\section{Introduction:}

During the past decade, laparoscopic cholecystectomy rapidly developed to become the standard procedure for management of symptomatic cholecystolithiasis. ${ }^{1}$ However, controversy still exists concerning the routine use of IOC, and the optimal therapy for simultaneous common bile duct (CBD) stones. ${ }^{2}$

This will exist also for the coming years as many factors like surgical expertise and the cost of instruments used add to the controversy regarding the proper role of (IOC) for patients undergoing LC; especially in identifying the anatomy and the abnormalities of biliary tract and thus reducing the rate of bile duct injuries. ${ }^{3,4}$ Also, it detects asymptomatic bile duct stones as the frequency of simultaneous presence of bile duct stones varies from 8 to $19 \%$ and increasing with age. 5 Before the introduction of endoscopic retrograde cholangiopancreatography (ERCP) with papillotomy and laparoscopic cholecystectomy (LC), open common bile duct exploration was considered the standard procedure. ${ }^{6}$

At present, including the above two minimally invasive techniques (ERCP with papillotomy and LC), three competing therapeutic concepts emerge. 7,8

1- Preoperative, intra-operative, and/ or postoperative endoscopic treatment of common bile duct stones followed by laparoscopic (or open) cholecystectomy.
2- Primary laparoscopic CBD exploration during laparoscopic cholecystectomy.

3- Open cholecystectomy and simultaneous treatment of CBD stones.

We retrospectively reviewed the results of 172 consecutive LC where IOC performed routinely with laparoscopic management of CBD stones when detected as a single stage procedure was achieved either through the cystic duct or choledochotomy. Our results are presented, discussed, and compared to data in the literature with emphasis on the role of routine IOC.

\section{Material and methods:}

Between July 2005 and June 2007, 172 patients (170 admitted to Landeskrankenhaus Bregenz - Austria; July 2005 - December 2006) \& (Two patients admitted to Ain Shams Specialized Hospital - Egypt; December 2006 - June 2007) who presented for elective or acute laparoscopic cholecystectomy were studied. There were 68 men $(40 \%)$ and 104 women $(60 \%)$ with mean age $49 \pm 18$ years Table(1). Intra-operative cholangiography was attempted routinely in all patients either through cannulation of the cystic duct in 154 patients $(89.5 \%)$ or through direct puncture of gall bladder (cholecystography) step by step in 3 patients $(1.7 \%)$ to identify the cystic duct in acute or difficult cases.

Table (1): Patient demographics and operative times.

\begin{tabular}{|c|c|c|}
\hline S. No. & Characteristics & Variables \\
\hline 1 & Age (ys.) & $49(14-97) \mathrm{a}$ \\
\hline 2 & Female/male & $104 / 68$ \\
\hline 3 & $\begin{array}{c}\text { Previous abdominal surgeries } \\
\text { - Lap. Nissen Fudoplication } \\
- \text { Umbilical hernia repair } \\
- \text { Appendicectomy }\end{array}$ & 2 \\
7 \\
\hline 4
\end{tabular}


A Median (range), B Mean (range), LC; laparoscopic cholecystectomy, IOC; intraoperative cholangiography.

Preoperative evaluation included abdominal ultrasonography, routine laboratory tests and liver function tests (LfTs). Contraindications for this procedure included suspicion of malignancy, severe pancreatitis and/ or cholangitis, and unfitness for anesthesia. Such patients were primarily selected for further diagnostic magnetic resonance cholangiopancreatography (MRCP), e n d o s c o p i c retrograd e cholangiopancreatography (ERCP) with optional papillotomy.

\section{Operative procedure:}

To perform a static IOC, after dissection of the cystic artery and duct, a titanium clip is applied to the cystic duct close to the gall bladder infundibulum. Then a 5-Fr ureteral catheter, which is passed into the abdominal cavity by a grasping forceps $(5 \mathrm{~mm}$, Storz Company, Tuttlingen, Germany) Figure(1A) or enters the intra-abdominal cavity next to the trocar (sub-xiphoid trocar) and pushed into the cystic duct through a small transverse incision on the anterior surface of cystic duct made by scissors until its distal hole pass into the lumen Figure(2A, B, C).
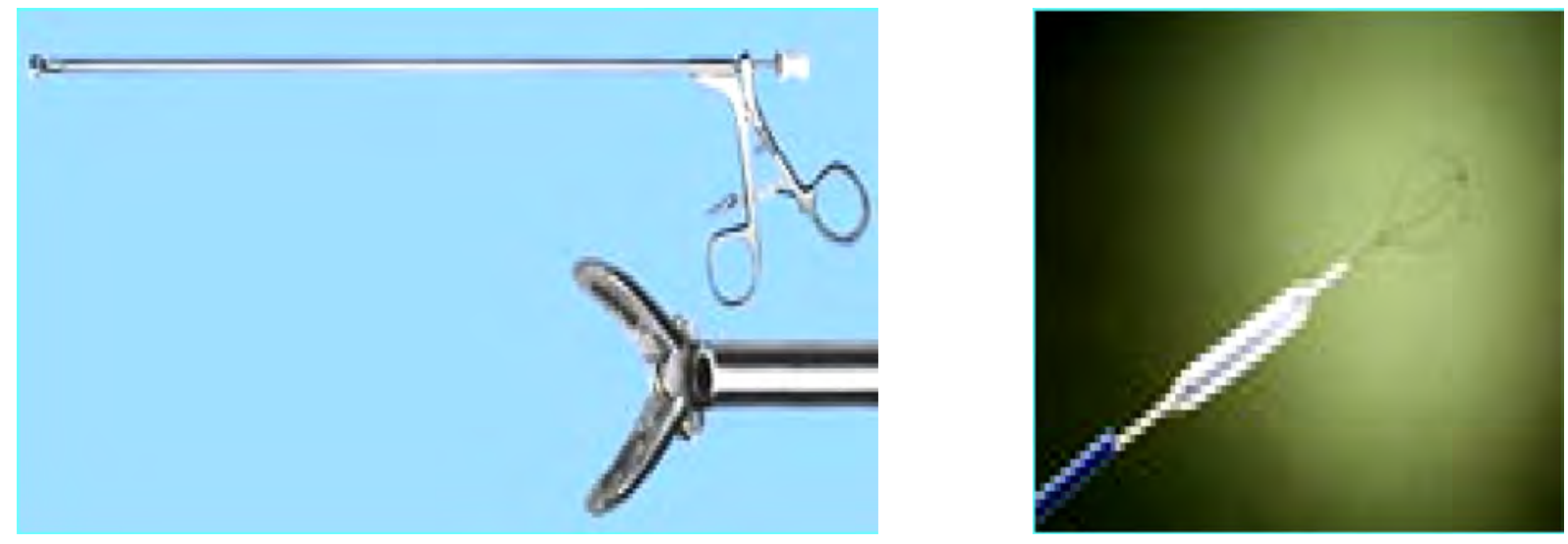

Figure (1): Instruments used in operative cholangiogram, A-grasping forceps. B-Fogarty catheter.

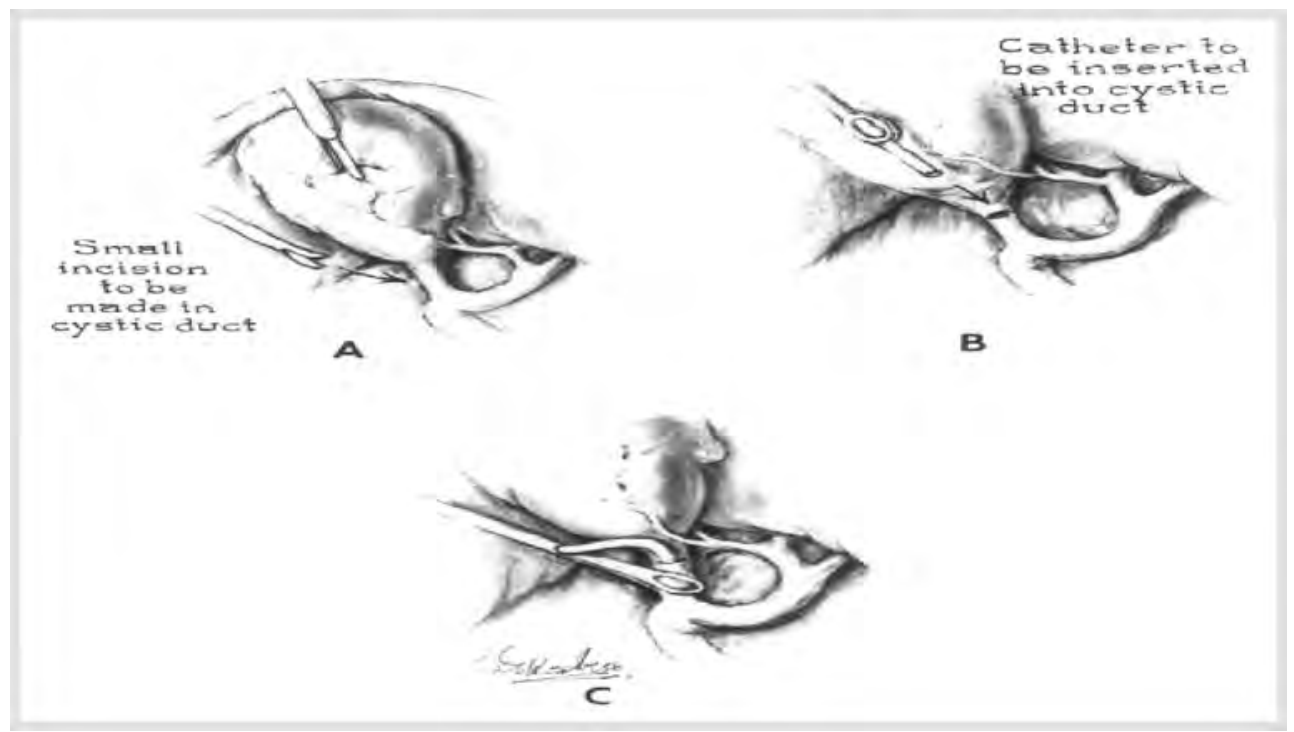

Figure (2) (A, B, C): Small transverse incision on the anterior surface of cystic duct made by scissors, catheter pushed in the lumen of the duct and fixed. 
The catheter fixed in its place by titanium clip or by the grasping forceps. Before administration of the contrast dye, 3-5 ml saline flushed into the lumen to examine the position of the catheter, its fixation and the patency of the lumen. If no water leaks, the grasper at the site of costal margins pulled to prevent its interference in the graphy. Following

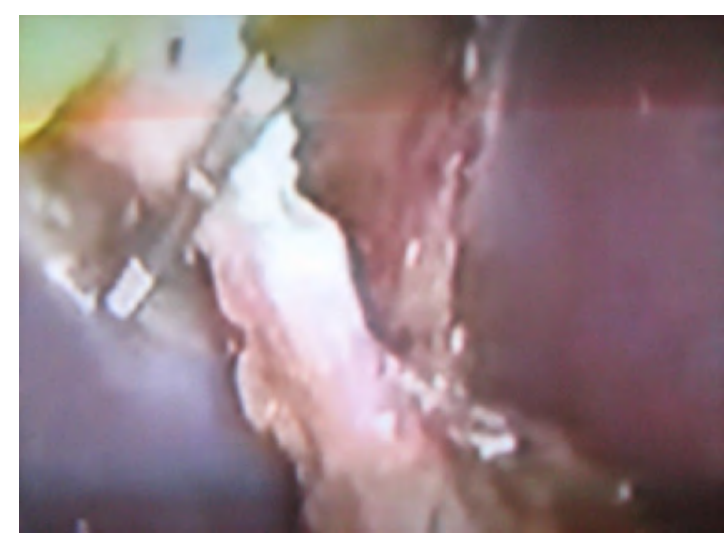

(A)

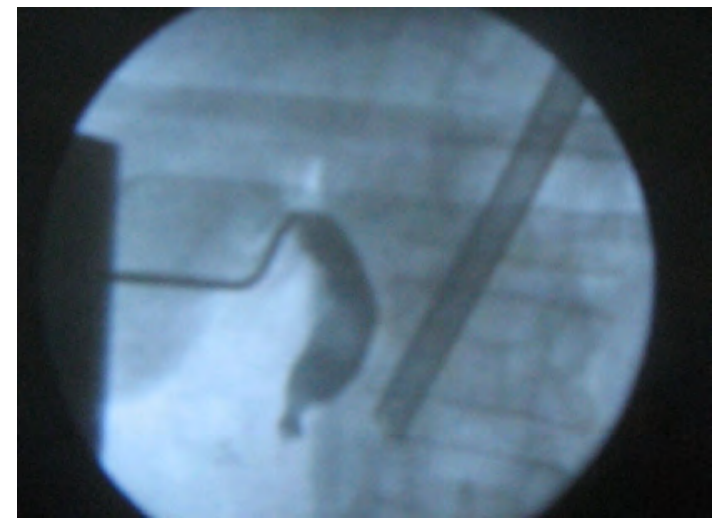

(C)

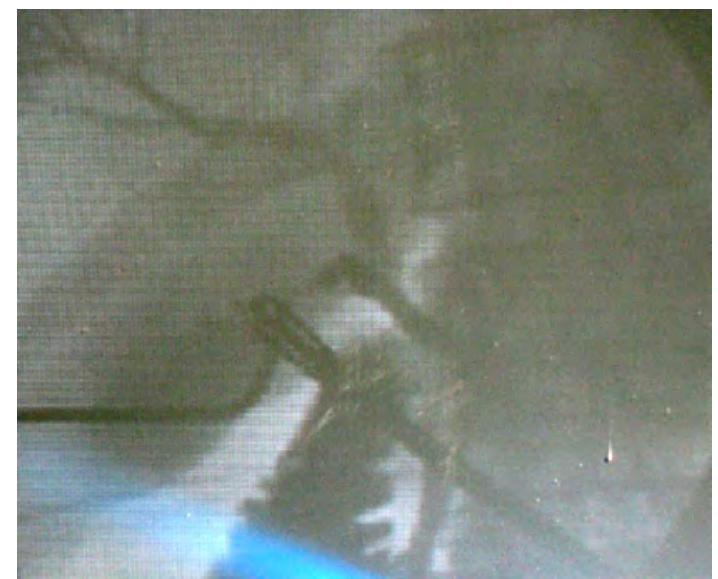

(E) administration of $2 \mathrm{ml}$ of contrast dye (Ibimiro) via a syringe into the catheter, a supine graphy is obtained with portable unit to visualize distal CBD and oddi's sphincter. Then the patient is placed in the trendelenberg position, and additional $3 \mathrm{ml}$ of contrast dye is administered to visualize the proximal CBD, right and left hepatic ducts and the junction Figure(3).

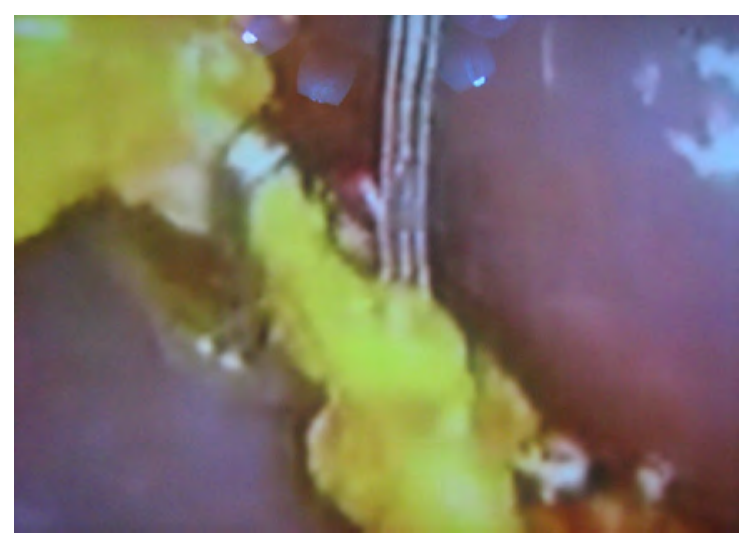

(B)

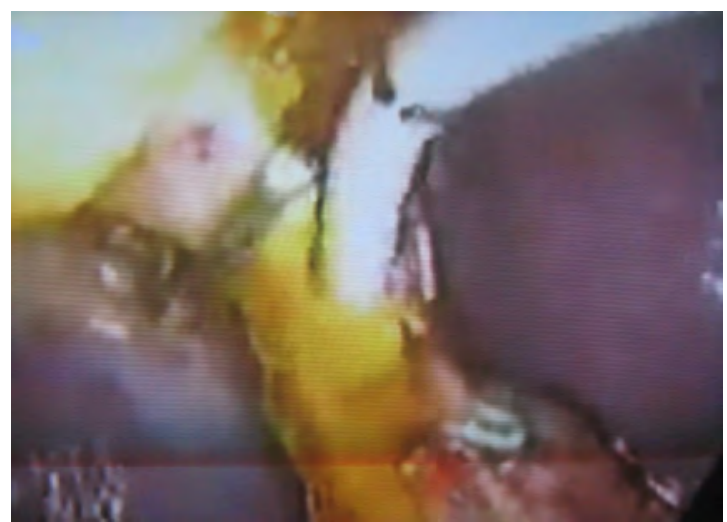

(D)

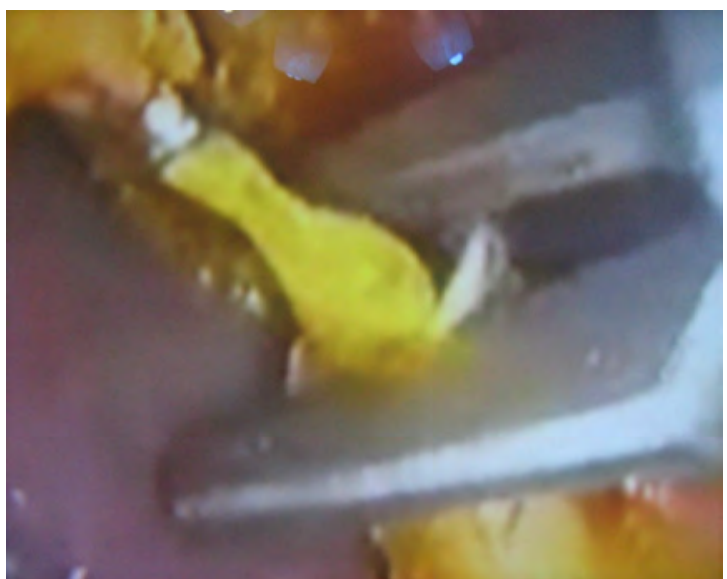

$(F)$

Figure (3) (A, B, C, D, E, F): A: Incision on the anterior surface of cystic duct. B: The catheter fixed in the cystic duct by titanium clip with injection of contrast media. C: Graph showing dilated CBD with obaque shadow (stone). D: Insertion of Fogarty catheter in the cystic duct and passing to the CBD to extract the stone. E: Graph showing clear CBD from stones and passage of dye to the duodenum. F: clipping of the cystic duct opening. 
In severely inflammed gall bladder with difficult dissection, the catheter passed through the apparent part of gall bladder and step by

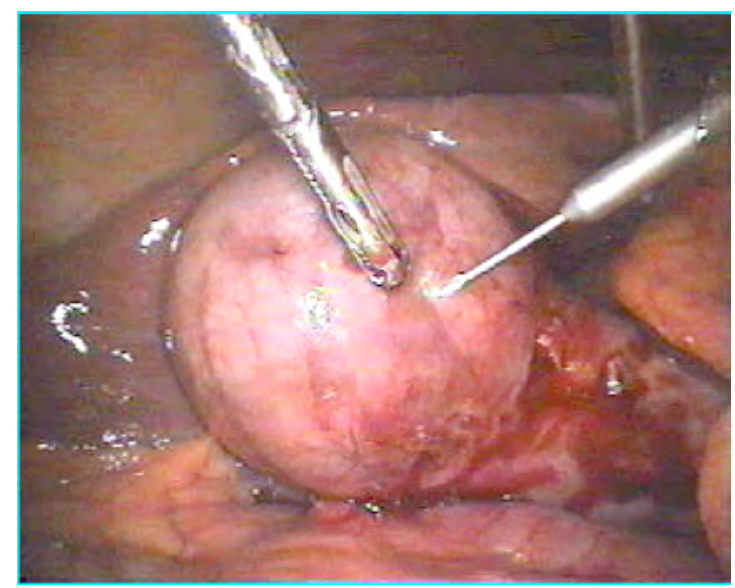

(A)

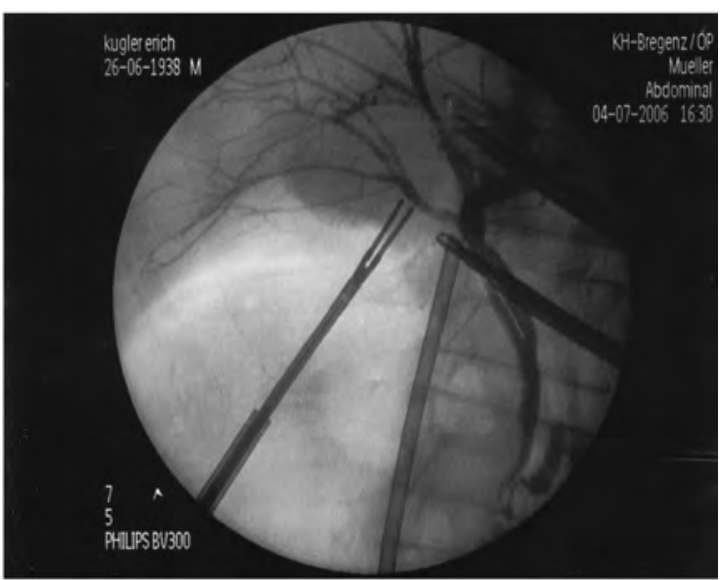

$(C)$ step moved forward to the cystic duct after clarifying of the cystic duct as position and length in relation to the CBD Figure $(\mathbf{4 A , B}, \mathbf{C}, \mathbf{D})$.

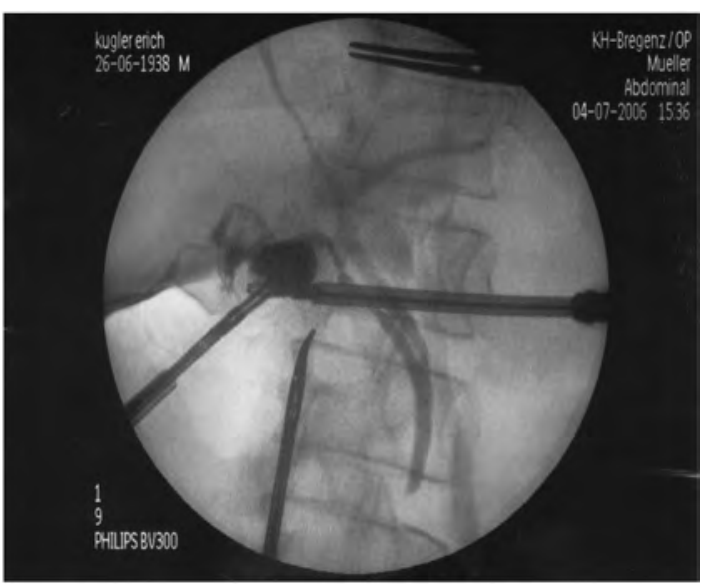

(B)

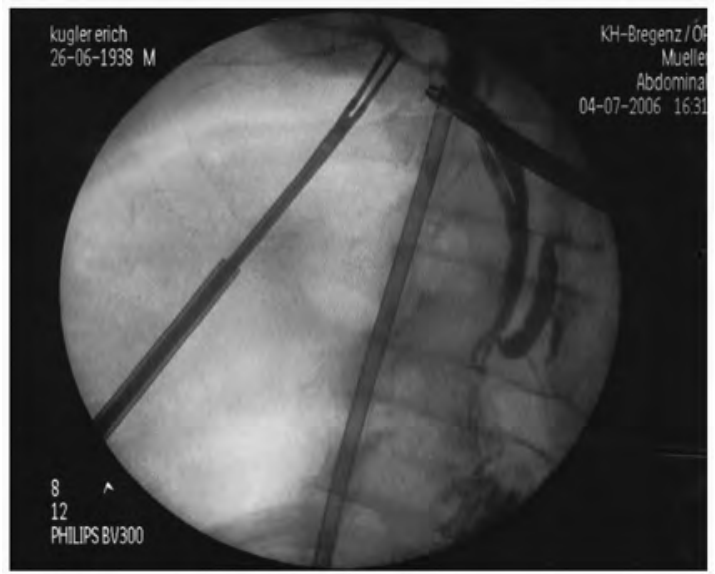

(D)

Figure (4) (A, B, C, D): Cholecystography for acutly inflamed gall bladder. A: Aspiration of gall bladder content. B: Graph showing the catheter and contrast dye in the gall bladder and the cystic duct appeared clear with good length from $C B D . C \& D$ : Catheter moved to the cystic duct and IOC showing proximal, distal CBD and Pancreatic duct with free passage of dye to the duodenum.

Cholangiograms were routinely evaluated during the operation, focusing on some findings:

- Anatomic variations Figure(5).

- Passage of contrast media into duodenum.

- CBD diameter and stones.

- Distal, proximal CBD and hepatic ducts visualization.

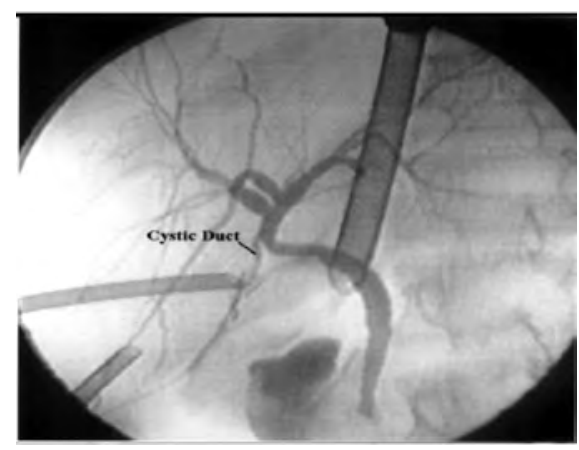

Figure (5): Picture of a cholangiogram showing how it clearly demonstrates the anatomy. In this particular case, an aberrant right hepatic duct is demonstrated. 
If CBD stones are detected, primary management via cystic duct is intended. Under $\mathrm{X}$ - ray guidance, a Dormia basket or Fogarty catheter Figure(1) is introduced and small stones measuring $<5-6 \mathrm{~mm}$ diameter are extracted or advanced through the papilla into the duodenum. We do not perform balloon dilatation of the cystic duct and also we regularly use Glucagon $1 \mathrm{mg}$ IV flush with warm saline. If Transcystic retrieval cannot be performed because of the size or position if the stones (i.e., common hepatic duct), removal is conducted via longitudinal CBD incision. Whether T-tube or double-balloon catheter introduced via the common bile duct incision and the incision closed by running suture (absorbable Vicreyl suture 3/0) Following transcystic management including a final cholangiography proving absence of stones, the cystic stump is closed using endoclips without insertion of a bile duct drainage tube. Drainage tube was routinely inserted into the subhepatic operative field after LC (with or without bile duct management). A four-trocar technique is sufficient in most cases $(10-\mathrm{mm}$ supraumbilical, 10-mm midline epigastric, two 5 -mm ports in the right upper quadrant of the abdomen) Four $\%$ to $6 \%$ of our procedures have been conducted using three and five trocars, respectively.
In our cases, intra-operative cholangiography (IOC) with photo documentations was kept with the patient's record. The first follow-up visit was 1 week postoperatively; then, follow-up occurs monthly and then every 3 months.

\section{Results:}

Between July 2005 and June 2007, 172 cholecystectomies were performed due to bile stone disease of which $160(93 \%)$ were conducted laparoscopically. Two additional conventional procedures were done within laparotomies based on other indications. During the same period simultaneous bile duct stones were detected in 26 individuals (15.1\%). In 11 of these patients (6.3\% of all cholecystectomies) diagnosis was attained only during operation. Twenty-Four patients underwent primary laparoscopic management.

Transcystic management was performed in 15 patients $(8.7 \%)$, common bile duct incision in 9 individuals (5.3\%), complete removal of CBD stones was achieved in 23 patients $(13.4 \%)$. In one patient $(0.58 \%)$ residual concrements were removed by EPT (endoscopic papillotomy) which conducted intraoperatively. In two cases $(1.1 \%)$ large stones were impacted and retrieved via laparotomy. So, with using this technique ERCP/ EPT was avoided in 23 patients Table(2).

Table (2): Operative characteristics.

\begin{tabular}{|l|c|c|}
\hline \multicolumn{1}{|c|}{ Operative Characteristics } & No. Of Patients & $\%$ \\
\hline 1) Successful Intra-operative Cholangiography: & 157 & 91.3 \\
& & \\
A - Bile duct stones: & 26 & 15.1 \\
* Retrieval was performed via cystic duct. & 15 & 8.7 \\
* Retrieval via common bile duct. & 9 & 5.3 \\
* Retrieval via Laparotomy. & 2 & 1.1 \\
B - Dilated ducts without stones. & 6 & 3.4 \\
C - Anatomic variations (Aberrant right hepatic duct). & 5 & 1.7 \\
D- Stone in the cystic duct. & 3 & 2.9 \\
E- Cholecystography (Dense adhesions at Calot's). & 129 & 1.7 \\
F- No difficulty in Cannulation of cystic duct \& No & & 75 \\
abnormality. & & \\
\hline
\end{tabular}




\begin{tabular}{|l|c|c|}
\hline \multicolumn{1}{|c|}{ Operative Characteristics } & No. Of Patients & $\%$ \\
\hline 2) Failed Intra-operative Cholangiography: & 15 & 8.7 \\
& 3 & 1.7 \\
A- Difficult cannulation of Cystic duct. & 12 & 6.9 \\
$\quad$ B- Conversion to open Cholecystectomy & 4 & 2.3 \\
* Dense adhesions at Calot's (severely inflamed gallbladder & 3 & 1.7 \\
$\quad$ or fibrosis of Calot's triangle) & 2 & 1.1 \\
* Inability to achieve working space due to dense intra- & 1 & 0.58 \\
abdominal adhesions & 2 & 1.1 \\
* Impacted ductal stones. & & \\
* Instrumental, Techniqual \& Radiographer variables. & & \\
\hline
\end{tabular}

Mean operation time including cholecystectomy was $140 \mathrm{~min}$ (range 55 to $250 \mathrm{~min}$ ). Peri- and postoperative complications were observed in $1.1 \%$ of patients $(n=172)$. Two patients were re-operated (one laparotomy and one relaparoscopy for treatment of severe bleeding and biliom formation respectively). One 64-year-old patient died as a result of a cardiac complication on the 8 th postoperative day $(0.5 \%)$.

\section{Discussion:}

Controversy still exists concerning the routine use of intraoperative cholangiography (RIOC). But considering the various and valuable information obtained by IOC like the unexpected biliary anatomy and the incidence of missed asymptomatic ductal stones, make the RIOC is cost-effective and is recommended in all LCs. ${ }^{9}, 10$

Asymptomatic ductal stone means that the patient has no history, sonographic evidence, or lab tests indicating the presence of ductal obstruction. ${ }^{11}$ A normal cholangiogram, routinely performed, almost always means a clear bile duct and so it can prevent unnecessary postoperative ERCP and its potential complications for the symptoms that can be attributed to retained ductal stones. ${ }^{12-15}$

Several other studies have shown that RIOC can detect significantly more biliary injuries as well as unexpected biliary anatomy and many of potential surgical relevance. ${ }^{16}$ During the 1990s, a higher rate of iatrogenic biliary tract injuries was reported, and this was attributed to the learning curve for LC. Stewart and Way in a review of patients, who were referred to their tertiary center with iatrogenic biliary tract injuries during a 7-year period, identified the two most important reasons for ductal injury during LC as (a) false identification of CBD as the cystic duct and (b) aggressive efforts to stop bleeding. They outlined 14 principles to avoid nearly all ductal injuries, the two most crucial of which are the liberal use of IOC and to cautiously interpret the lack of opacification of the proximal CBD as a sign of its closure. ${ }^{17}$

There are also arguments that RIOC wastes time and money. ${ }^{18}$ It has been estimated that if one severe bile duct injury is prevented in every 1,000 LCs, the cost of all "unnecessary" IOCs will be saved. A cost-effectiveness analysis estimated that RIOC would cost $\$ 100$ more per LC. However, it would save $\$ 390,000$ per death avoided and $\$ 87,143$ per CBD injury avoided. The extra charge for a static IOC during LC in our center in Ain Shams University Hospital - Egypt is approximately $\$ 55$ and in Landeskrankenhaus Bregenz Austria is approximately 85 Euro including radiology department fees (including the fee for a portable radiological device per single use, radiology technician, two cassettes, and development of two radiological films) and operating room instruments used (one ureteral catheter, one angiocath, and $10 \mathrm{ml}$ of contrast dye). ${ }^{17-20}$

Also, bile duct stones are detected more frequently when IOC is employed routinely rather than selectively and management of these unexpected ductal stones founded during 
LC in the era of laparoscopic surgery is still controversial. Before the establishment of new endoscopic techniques (ERCP / endoscopic papillotomy "EPT") and laparoscopy, open surgery represented the gold standard for management of choledocholithiasis.2,21 Nowadays, preoperative ERCP / EPT followed by LC are considered to be the concept of choice for most surgeons. ${ }^{22}$ This two-step procedure is generally accepted because of its significant lower complication and mortality rate when compared to open bile duct surgery. ${ }^{11,18,23,24}$ In contrast, a Germanywide survey reports a surprisingly high rate for initial open bile duct management of $\sim 11.6 \% .15$ In $74.4 \%$ of institutions initial ERCP/ EPT and subsequent LC were considered as first choice treatment, if bile duct stones were diagnosed prior to operation; $58.4 \%$ decided for Endoscopic papillotomy when stones were detected intraoperatively. ${ }^{20,23-25}$

Although ERCP is quite efficient in the management of ductal stones, it has a morbidity rate of $7-11 \%$ and a mortality of $<1 \%$, especially if accompanied by endoscopic sphincterotomy (ES) and thus postoperative ERCP can be reserved for those who become symptomatic during the follow-up period. ${ }^{24}$

Because of increasing surgical experience, technical improvements in laparoscopy, and general acceptance of LC as a standard procedure, laparoscopic CBD exploration should gain wider application. Intraoperative cholangiography is absolutely necessary for laparoscopic bile duct surgery and is therefore routinely performed in our series. Though it was considered standard procedure during the time of open cholecystectomy, at present, intraoperative cholangiography is routinely performed in only $6 \%$ and selectively in $49 \%$ of institutions. ${ }^{15}$ This procedure provides safe orientation in the presence of difficult anatomy and lowers the risk and rate of undetected iatrogenic lesions of the common bile duct. ${ }^{25-27}$ In addition, it improves the prognosis of bile duct lesions by facilitating intraoperative diagnosis and repair. ${ }^{28}$ Furthermore, intraoperative cholangiography requires detailed identification of the cystic duct, thus enabling the surgeon to assess anatomical variations $18,29,30$

When routine and surgical skills are available, additional operation time and costs are kept low and prove to be justified by reducing intraoperative complications. ${ }^{31}$ Taking into account a complication rate varying between $3.4 \%-11.7 \%$, a long-term time morbidity of up to $15 \%$ and mortality rate of $0.9 \%$ for endoscopic papillotomy (EPT) alone without cholecystectomy, so strong efforts for patient health ensuring simultaneous management via the cystic duct are understandable. ${ }^{31-34}$

Controversy still exists concerning impaired function of the papilla following EPT: Soehendra et al. ${ }^{35}$ report absence of papilla function impairment. In contrast, other groups report reflux of duodenal secretion into bile ducts and presence of bacteria in the bile duct system in $70 \%$ of cases, ${ }^{36-38}$ and significant biliary symptomatology in $15 \%$ of patients. $35,37,38$ Tranter and Thompson reported a late development of bile duct cancer in up to two per cent of patients following EPT, possibly based on the chronic mucosal inflammation. ${ }^{39}$ In contrast, laparoscopic CBD exploration provides anatomical and functional integrity of the papilla. ${ }^{40}$

The reported results of laparoscopic CBD exploration are comparable to data obtained after a two-stage procedure (success rate between $82 \%$ and $95 \%$ ), show at least identical rather improved safety for the patient, and partial reduction of costs. $1,7,10,14,31,39$ In a prospective randomized trial including 40 patients per treatment arm, Rhodes et al. ${ }^{41}$ show similar success rates and operation times and significant shorter hospitalization time for individuals treated by laparoscopy. Cuschieri et al. ${ }^{13}$ reports on a prospective randomized multicenter trial, showing similar success and complication rates and a significant reduction of hospital stay for the single-stage management of CBD stones. Furthermore, it is shown that particularly patients with ASA stage I and II benefit from simultaneous laparoscopic therapy. According to a recent publication, laparoscopic CBD exploration can also be conducted safely with a low complication rate in older patients. ${ }^{19}$

Stress and morbidity are equal to LC without CBD exploration. Similarly, morbidity 
following choledochotomy is comparable to data obtained after a two-stage procedure and less, when compared to open surgery. ${ }^{42-46}$ However, advantageous impact on shorter hospital stay is not observed.

In our series of $26 \mathrm{CBD}$ explorations, stones were detected only intraoperatively in $42 \%$. This represents $6.3 \%$ of all cholecystectomies. Because of routine intraoperative cholangiography, and simultaneous CBD exploration in positive cases, negative preoperative endoscopies are avoided and the requirement for endoscopic retrieval of remaining stones is reduced to a minimum (in our series, $0.58 \%$ ). Furthermore, using this approach, ERCP and EPT, as well as procedure-associated risks, could be avoided in 23 patients $(92 \%)$.

According to the recommendations of international surgical societies, $8,26,30$ the decision for preoperative EPT or simultaneous laparoscopic management of CBD stones is left to the surgeon, depending on his experience in laparoscopy and the availability of technical equipment. ${ }^{30}$

\section{Conclusion:}

RIOC is a safe, accurate, quick, and costeffective method for the detection of bile duct anatomy and stones. A highly disciplined performance of RIOC, especially in the hands of an experienced laparoscopic surgeon, can well minimize the potentially debilitating and hazardous complications of bile duct injury.

Also, in terms of outcome and safety, laparoscopic management of cystic and common bile duct stones must be considered equal to common two-stage procedure with preoperative endoscopic papillotomy (EPT). Transcystic management, notably, does not stress the patient more than cholecystectomy alone and should, therefore, always be attempted. Based on our experience, the complication rate of laparoscopic common bile duct exploration and cholecystectomy equals data reported for ERCP and EPT without cholecystectomy. In addition, the laparoscopic approach provides preservation of the papilla. Therefore we are convinced that this singlestage procedure represents a profound development in the therapy of choledocholithiasis.

\section{References:}

1- Mirizzi PL: Calculi of the common bile duct (520 cases under the control of surgical cholangiography). Mem Acad Chir 1995; (Paris) 81: 834-841.

2- NIH Consensus Development Panel on Gallstones, Laparoscopic Cholecystectomy Gallstones and laparoscopic cholecystectomy. Surg Endosc 1993; 7 : 271-279.

3- Shively EH, Wieman TJ, Adams AL, Romines RB, Garrison RN: Operative cholangiography. Am J Surg 1990; 159: 380-384.

4- Vezakis A, Davides D, Ammori BJ, Martin IG, Larvin M, McMahon MJ: Intraoperative cholangiography during laparoscopic cholecystectomy. Surg Endosc 2000; 14: 1118-1122.

5- Jones DB, Dunnegan DL, Soper NJ: Results of a change to routine fluorocholangiography during laparoscopic cholecystectomy. Surgery 1995; 118 : 693702.

6- Woods MS, Traverso LW, Kozarek RA, Donohue JH, Fletcher DR, Hunter JG, Oddsdottir M, Rossi RL, Tsao J, Windsor $\mathrm{J}$ : Biliary tract complications of laparoscopic cholecystectomy are detected more frequently with routine intraoperative cholangiography. Surg Endosc 1995; 9 : 1076-1080.

7- Soper NJ, Dunnegan DL: Routine versus selective intraoperative cholangiography during laparoscopic cholecystectomy. World J Surg 1992; 16 : 1133-1140.

8- Hauer-Jensen M, Karesen R, Nygaard K, Solheim K, Amlie EJ, Havig O, Rosseland AR: Prospective randomized study of routine intraoperative cholangiography during open cholecystectomy: long-term follow-up and multivariate analysis of predictors of choledocholithiasis. Surgery 1993; 113: 318-323.

9- Kullman E, Borch K, Lindstrom E, Svanvik $\mathrm{J}$, Anderberg B: Value of routine intraoperative cholangiography in detecting aberrant bile ducts and bile duct injuries during laparoscopic cholecystectomy. $\mathrm{Br}$ J Surg 1996; $83: 171-175$.

10-Stuart SA, Simpson TI, Alvord LA, Williams MD: Routine intraoperative 
laparoscopic cholangiography. Am J Surg 1998; $176:$ 632-637.

11-Snow LL, Weinstein LS, Hannon JK, Lane DR: Evaluation of operative cholangiography in 2043 patients undergoing laparoscopic cholecystectomy: a case for the selective operative cholangiogram. Surg Endosc 2001; 15 : 14-20.

12-Cuschieri A, Lezoche E, Morinjo M, Croce E, Lacy A, Toouli J, Faggioni A, Ribeiro VM, Jakimowicz J, Visa J, et al.: E.A.E.S. multicenter prospective randomized trial comparing two-stage vs single-stage management of patients with gallstone disease and ductal calculi. Surg Endosc 1999; 13 : 952-957.

13-Erickson RA, Carlson B: The role of endoscopic retrograde cholangiopancreatography in patients with laparoscopic cholecystectomies. Gastroenterology 1995; 109 : 252-263.

14-Ammori BJ, Birbas K, Davides D, Vezakis A, Larvin M, McMahon MJ: Routine vs "on demand" postoperative ERCP for small bile duct calculi detected at intraoperative cholangiography. Clinical evaluation and cost analysis. Surg Endosc 2000; 14 : 1123 1126.

15-Flowers JL, Zucker KA, Graham SM, Scovill WA, Imbembo AL, Bailey RW: Laparoscopic cholangiography. Results and indications. Ann Surg 1992; 215 : 209216.

16-Rhodes M, Sussman L, Cohen L, Lewis MP: Randomized trial of laparoscopic exploration of common bile duct versus postoperative endoscopic retrograde cholangiography for common bile duct stones. Lancet 1998; 351 : 159-161.

17-Stewart L, Way LW: Bile duct injuries during laparoscopic cholecystectomy. Factors that influence the results of treatment. Arch Surg 1995; 130 : 11231128.

18-Robinson BL, Donohue JH, Gunes S, Thompson GB, Grant CS, Sarr MG, Farnell MB, van Heerden JA: Selective operative cholangiography. Appropriate management for laparoscopic cholecystectomy. Arch Surg 1995; 130: 625-631.

19-Phillips EH, Berci G, Carroll B, Daykhovsky L, Sackier J, Paz-Partlow M:
The importance of intraoperative cholangiography during laparoscopic cholecystectomy. Am Surg 1990; 656 : $792-$ 795.

20-Phillips EH: Routine versus selective intraoperative cholangiography. Am J Surg 1993; $165:$ 505-507.

21-Deziel DJ, Millikan KW, Economou SG, Doolas A, Ko ST, Airan MC: Complications of laparoscopic cholecystectomy: a national survey of 4,292 hospitals and an analysis of 77,604 cases. Am J Surg 1993; 165 : 9-14.

22-Ludwig K, Bernhardt J, Steffen H, Lorenz D: Contribution of intraoperative cholangiography to incidence and outcome of common bile duct injuries during laparoscopic cholecystectomy. Surg Endosc 2002; 16 : 1098-1104.

23-Coppola R, Riccioni ME, Ciletti S, Cosentino L, Coco C, Magistrelli P, Picciocchi A: Analysis of complications of endoscopic sphincterotomy for biliary stones in a consecutive series of 546 patients. Surg Endosc 1997; 11 : 129-132.

24-Costamagna G, Tringali A, Shak SK, Mutignani M, Zuccala G, Perri V: Longterm follow-up of patients after endoscopic sphincterotomy for choledocholithiasis, and risk factors for recurrence. Endoscopy 2002; 34: 273-279.

25-EAES: Diagnosis and treatment of common bile duct stones (CBDS). Results of a consensus development conference. Scientific Committee of the European Association for Endoscopic Surgery (EAES). Surg Endosc 1998; 12 : 856-864.

26-Flum DR, Flowers C, Veenstra DL: A costeffectiveness analysis of intraoperative cholangiography in the prevention of bile duct injury during laparoscopic cholecystectomy. J Am Coll Surg 2003; $196: 385-393$.

27-Clair DG, Carr-Locke DL, Becker JM, Brooks DC: Routine cholangiography is not warranted during laparoscopic cholecystectomy. Arch Surg 1993; 128: 551-554.

28- Cuschieri A, Shimi S, Banting S, Nathanson LK, Pietrabissa A: Intraoperative cholangiography during laparoscopic cholecystectomy. Routine vs selective policy. Surg Endosc 1994; 8: 302-305. 
29-Berthou JC, Drouard F, Charbonneua P, Moussalier K: Evaluation of laparoscopic management of common bile duct stones in 220 patients. Surg Endosc 1998; 12 : 16-22.

30-Cuschieri A, Lezoche E, Morino M, Croce E, Lacy A, Toouli J, Faggioni A, Ribeiro VM, Jakimowicz J, Visa J, Hanna GB: E.A.E.S. multicenter prospective randomized trial comparing two-stage vs single-stage management of patients with gallstone disease and ductal calculi. Surg Endosc 1999; 13 : 952-957.

31-Huttl TP, Hrdina CH, Geiger TK, Meyer G, Schildberg FW, Kramling HJ: Management of common bile duct stones. Results of a nationwide survey with analysis of 8433 common bile duct explorations in Germany. Zentralbl Chir 2002; 127 : 282288.

32-Heili MJ, Wintz NK, Fowler DL: Choledocholithiasis: endoscopic versus laparoscopic management. Am Surg 1999; $65: 135-138$.

33-Kramling HJ, Lange V Heberer G: Current status of gallstone surgery in Germany. Results of a survey and retrospective analysis of 27,403 interventions-open vs. laparoscopic surgery. Chirurgie 1993; 64: 295-302.

34-Lezoche E, Paganini AM: Technical considerations and laparoscopic bile duct exploration: transcystic and choledochotomy. Semin Laparosc Surg 2000; 7: 262-278.

35-Soehendra N, Seifert H, Thonke F, Seitz U, Wang YG: Endoscopic techniques in therapy of choledocholithiasis. Chirurgie 1994; 65 : 413-417.

36-Ludwig K, Koeckerling F, Hohenberger W, Lorenz D: Surgical therapy in cholecysto-/choledocholithiasis. Results of a Germany-wide questionnaire sent to 859 clinics with 123,090 cases of cholecystectomy. Chirurgie 2001; 72: 1171-1178.

37-Ludwig K, Bernhardt J, Steffen H, Lorenz D: Contribution of intraoperative cholangiography to incidence and outcome of common bile duct injuries during laparoscopic cholecystectomy. Surg Endosc 2002; 16 : 1098-1104.
38-Neoptolemos JP, Carr-Locke DL, Fossard DP: Prospective randomized study of preoperative endoscopic sphincterotomy versus surgery alone for common bile duct stones. Br Med J 1987; 234 : 470-477.

39-Tranter SE, Thompson MH: Comparison of endoscopic sphicterotomy and laparoscopic exploration of the common bile duct. Br J Surg 2002; 89 : 1495-1504.

40-Paganini AM, Feliciotti F, Guerrieri M, Tamburini A, Campagnacci R, Lezoche E: Laparoscopic cholecystectomy and common bile duct exploration are safe for older patients. Surg Endosc 2002; 16 : 1302-1308.

41-Pereira-Lima JC, Jakobs R, Winter UH, Benz C, Martin WR, Adamek HE, Riemann JF: Long-term results (7 to 10 years) of endoscopic papillotomy for choledocholithiasis. Multivariate analysis of prognostic factors for the recurrence of biliary symptoms. Gastrointest Endosc 1998; 48: 457-464.

42-Pereira-Lima JC, Rynkowski CB, Rhoden EL: Endoscopic treatment of choledocholithiasis in the era of laparoscopic cholecystectomy: prospective analysis of 386 patients. Hepatogastroenterology 2001; 48 : 12711274.

43-Rhodes M, Sussmann L, Cohen L, Lewis MP: Randomized trial of laparoscopic exploration of common bile duct versus postoperative endoscopic retrograde cholangiography for common bile duct stones. Lancet 1998; 351 : 159-161.

44-Riciardi R, Islam S, Canete JJ, Arcand PL, Stoker ME: Effectiveness and long-term results of laparoscopic common bile duct exploration. Surg Endosc 2003; 17 : 1922.

45-Wills VL, Gibson K, Karihaloot C, Jorgensen JO: Complications of biliary Ttubes after choledochotomy. ANZ J Surg 2002; 72 : 177-180.

46-Tokumura H, Umezawa A, Cao H, Sakamoto N, Imaoka Y, Ouchi A, Yamamoto K: Laparoscopic management of common bile duct stones: transcystic approach and choledochotomy. J Hepatobil Pancreat Surg 2002; 9 : 206-212. 